2009-07

\title{
Categorization of regional and foreign accent in 5- to 7-year-old British children
}

Floccia, Caroline

http://hdl.handle.net/10026.1/9958

10.1177/0165025409103871

International Journal of Behavioral Development

SAGE Publications

All content in PEARL is protected by copyright law. Author manuscripts are made available in accordance with publisher policies. Please cite only the published version using the details provided on the item record or document. In the absence of an open licence (e.g. Creative Commons), permissions for further reuse of content should be sought from the publisher or author. 


\title{
Categorization of regional and foreign accent in 5- to 7-year-old British children
}

\author{
Caroline Floccia ${ }^{\mathrm{a}}$, Joseph Butlera, Frédérique Girard ${ }^{\mathrm{b}}$ and Jeremy Goslin ${ }^{\mathrm{a}}$
}

\begin{abstract}
This study examines children's ability to detect accent-related information in connected speech. British English children aged 5 and 7 years old were asked to discriminate between their home accent from an Irish accent or a French accent in a sentence categorization task. Using a preliminary accent rating task with adult listeners, it was first verified that the level of accentedness was similar across the two unfamiliar accents. Results showed that whereas the younger children group behaved just above chance level in this task, the 7-year-old group could reliably distinguish between these variations of their own language, but were significantly better at detecting the foreign accent than the regional accent. These results extend and replicate a previous study (Girard, Floccia, \& Goslin, 2008) in which it was found that 5 -year-old French children could detect a foreign accent better than a regional accent. The factors underlying the relative lack of awareness for a regional accent as opposed to a foreign accent in childhood are discussed, especially the amount of exposure, the learnability of both types of accents, and a possible difference in the amount of vowels versus consonants variability, for which acoustic measures of vowel formants and plosives voice onset time are provided.
\end{abstract}

Keywords: accent; categorization; children; dialect; speech perception

Numerous anecdotal reports claim that when listening to a speaker with an unfamiliar accent, in a conference for example, it takes a few sentences or minutes before we feel as if our understanding has improved. These real-life experiences suggest that, as adults, we seem able to train ourselves relatively quickly to process unfamiliar accent-related variations. Long-term exposure also has an effect on accent processing, as demonstrated by Clopper and Pisoni (2004) who showed that the amount of exposure to dialect variability through multiple moves around the country could predict how accurately young American adult listeners would categorize accents. However, results from studies of accent adaptation in laboratory situations are far less clear. On the one hand, Maye, Aslin, and Tanenhaus (2008) report an improvement in listeners' interpretation of lexical forms after exposure to a synthetic voice which was altered to reflect accented speech (see also Clarke \& Garrett, 2004). On the other hand Adank and McQueen (2007) failed to observe any improvement in an animacy task performed on isolated accented words in Dutch listeners (the accent under study was an unfamiliar Dutch regional accent), after 20 minutes of exposure to various speakers (see also Floccia, Butler, Goslin, \& Ellis, in press; Jongman, Wade, \& Sereno, 2003).

In contrast, multiple findings report consistently that regional and foreign accents induce perturbations in lexical access processes (e.g., Adank \& McQueen, 2007; Clarke \& Garrett, 2004; Floccia, Goslin, Girard, \& Konopczynski,

\footnotetext{
a University of Plymouth, UK. ${ }^{\mathrm{b}}$ University of Reims-Champagne-Ardennes, France.
}

2006), but little evidence demonstrates that these perturbations can adapt in adults, or, in other words, that mature speech perception mechanisms can learn to improve with repeated exposure. Do children process accent-related variations the same way as adults? It is well established that children are able to acquire new dialects if they have moved from one region to another, with proficiency generally inversely related to age. For example, Trudgill (1986) found that 7 -year-old twins had both acquired Australian vowels within six months of their arrival from the UK, even though they displayed different patterns of acquisition. Similarly, Chambers (1992) examined accent production in six 7- to 15-year-old Canadian English-speaking youngsters when moved to southern England. He found that all the children acquired new dialectal features, although the younger children were more likely to acquire the more complex phonological features than their older siblings (see also Payne, 1980).

This suggests that children, until early puberty, do possess the ability to adapt to new accent features, which must be paralleled to their impressive ability to learn the sound system of a second language (e.g., Flege, Yeni-Komshian, \& Liu, 1999). It is well known that the adaptability of the perceptual system is such that most children develop the ability to speak the second language without a foreign accent, whereas, if second language learning occurs later in life, chances are that the speaker will retain a foreign accent. This extreme plasticity of the early perceptual mechanisms is possibly what explains, in turn, children's ability to learn a new dialect in their native language (e.g., Chambers, 1992).

In order to understand better the processes underlying accent learning abilities, recent attempts have been made to

Correspondence should be sent to Caroline Floccia, University of Plymouth, School of Psychology, Drake Circus, Plymouth PL4 8AA, United Kingdom; e-mail: caroline.floccia@plymouth.ac.uk

This research was supported by a British Academy research grant.
The authors would like to thank the Plymouth schools, parents and children, who allowed us to carry out this research. We would also like to thank Bill Simpson, Allegra Cattani, John Clibbens, Kathryn O'Connor and Zoe Sax. 
trace children's discrimination capacities for various dialects across childhood. Results so far suggest a U-shaped curve in the ability to perceive regional variations of the maternal language between infancy and adulthood. Following Nazzi, Jusczyk, and Johnson's (2000) demonstration of American English versus British English sentences discrimination in 5month-old American infants, Kitamura, Panneton, Notley, and Best (2006) reported that this ability might disappear between 6 to 8 months. In their study, Australian infants were shown to discriminate American English from Australian English at 3 months, but failed to do so at 6 months (see also Phan \& Houston, 2006). Similarly, American infants could perform the same discrimination at 5 months, but failed at 7 months. These data were taken as evidence for a convergence of the construction of a single sound system, filtering out irrelevant phonetic differences due to the start of lexical acquisition (see also Butler, Metz, \& Floccia, 2008).

Although less is known about children and infants' perception of foreign accented speech, a recent study suggests that the developmental pattern might be different. Kinzler, Dupoux, and Spelke (2007) habituated American- and French-learning 5- to 6-month-olds with faces speaking their maternal language or a foreign-accented version of it. When presented with a silent smiling version of the faces, infants preferred those which had been coupled with the native speech samples over the foreign accented ones, suggesting that they were sensitive to the acoustic correlates of a foreign accent. In a subsequent experiment, 5-year-old American children were asked to choose a friend among pictures of children paired with voices in either American- or French-accented English. Again, children preferred to choose the children with the native accent over the ones with the foreign accent, suggesting an ongoing sensitivity for foreign accents during childhood.

In a recent study, we added credence to these claims by directly comparing children's perception of regional and foreign accent. Five-year-old French children from the Franche-Comté area (an Eastern region of France) were reported to discriminate and use a foreign (English) accent in a sentence categorization task, but surprisingly failed to perform a similar task with a Southern French regional accent (Girard et al., 2008). More specifically, their task was to listen to a series of sentences produced by pairs of female speakers in their home accent versus the unfamiliar regional accent, or in their home accent versus the foreign accent, and categorize them as belonging to a "blue teachers group" or an "orange teachers group". Children presented with the regional unfamiliar accent were at chance level (mean $A^{\prime}=.56$ ), whereas those presented with the foreign accent achieved a greater categorization performance (mean $A^{\prime}=.72$ ). This relative failure in the regional accent group was not due to children's inability to perceive differences between their home accent and the Southern French samples, because a separate group of children tested in an accent discrimination AX task performed above chance level when asked to discriminate their home accent from the unfamiliar regional accent in paired sentences (Exp. 4 in Girard et al., 2008). It was concluded that by the age of 5 children are able to perceive differences between varieties of accents in their maternal language, but that they have a greater awareness for the characteristics of foreign accented speech than for regionally accented speech. However, one potential pitfall in that study was that the foreign accented (English) speakers of French used in that study had a much stronger subjective accent than the Southern French speakers who had a moderate accent. Therefore, rather than being more sensitive to foreign accents than to regional accents in general, children might have been more accurate in detecting the foreign accent because its acoustic correlates were more salient than those of the regional accent.

To sum up, the ability to distinguish regional variations within the native language seems to emerge during the first six months life (Kitamura et al., 2006; Nazzi et al., 2000), after which infants seem to lose the ability to perform these distinctions (Butler et al., 2008; Kitamura et al., 2006; Phan \& Houston, 2006). This lack of sensitivity for an unfamiliar native accent seems to last at least until 5 years old, as shown by French children's inability to make use of a regional accent in a sentence categorization task (Girard et al., 2008). In contrast, infants' and children's sensitivity to foreign accents seems more stable during childhood (Girard et al., 2008; Kinzler et al., 2007), although the data reported by Girard et al. (2008) which directly compare categorization of regional and foreign accent might be due to a difference in accent strength rather than to a difference in accent type.

What would be the basis and the consequences of such a different sensitivity for regional and foreign accents? As suggested by Chambers, children might come equipped with an innate accent-filter, which prevents them from learning any "foreign features" (2002, pp. 121-122). Indeed, anecdotal evidence suggests that children born of immigrant, non-nativespeaking parents do not appear to learn the native language with their parent's foreign accent, whereas learning a new regional accent during childhood is a common observation (e.g., Fischer, 1958; Kerswill \& Williams, 1992; Starks, 2002). This foreign features filter might signal different underlying normalization abilities for the two types of accents: children might be able to normalize regional features prior to or in the course of lexical access, whereas they would be unable to process foreign-accent-related variability in a way that would preserve lexical identification procedures. A foreign pronunciation of the word "house", for example, would block lexical access because of the incapacity to retrieve appropriate phonological information from approximate phonetic information, whereas a regional variation of the same word would trigger normalization procedures leading to the identification of the intended item.

The aim of the present study is to provide additional data regarding the possible asymmetry between regional and foreign accent processing in young children by testing 5- to 7-year-old children in an accent categorization task. Two major extensions have been made in regard to the Girard et al.'s study. First, the speakers will be selected so that the strength of their accent will be as similar as possible across accent type. Second, another linguistic community was tested, namely British children instead of French children. One of the major and well-known problems when working with accents and dialects is the inevitable inter-speaker and inter-accent variability. Accents differ from each other on several dimensions: systemic (if speakers have a different set of phonemes), realizational (if the same phoneme has different phonetic realizations), lexical (if the same word is produced with a different series of phonemes), and intonational (see Grabe \& Post, 2002; Hughes \& Trudgill, 1996). It is therefore difficult to establish whether the results obtained with one set of accents can be generalized to other sets, or whether they are due to the particular characteristics found in a given accent. One way to circumvent this issue is to test whether the same effects can be reproduced with 
a different linguistic community (see Floccia et al., 2006; Kinzler et al., 2007, for a similar approach).

\section{Experiment}

In the current study, British children were tested in an accent categorization task, departing from the study by Girard et al. (2008) in a number of ways. First, two age ranges will be tested: 5 -year-olds and 7-year-olds, to look for a possible age effect. Second we will introduce a baseline to estimate each child's understanding of the task, by asking him/her to perform a gender categorization task (that is, sorting out voices using the gender of the speaker). Third, we will attempt to equalize the accentedness of the different speakers, that is, speakers will be selected if they have a moderate level of accent in both the regional and the foreign accent condition, and their accentedness will be controlled by appropriate accent rating tests.

If the asymmetry between perception of foreign and regional accent effect can be generalized across languages and accents, we expect to observe a greater awareness for the foreign accent than for the regional accent in the 5-year-old group (to follow Girard et al.'s results), and possibly in the 7-year-old group.

\section{Method}

\section{Participants}

Ninety-nine children were tested, and the data of 12 were rejected for success rate during baseline inferior to $80 \%$ (seven children, including four Reception Year children), loss of interest during the test phase (two), refusal to participate (one), and misunderstanding of the task (one child who started pressing keys randomly without listening to the sentences, and another one who only used one key). Forty of the remaining 87 children were in Reception Year (RY) (the equivalent of Pre $\mathrm{K}$ in the USA; mean age $5 ; 2$ years, from $4 ; 9$ to $5 ; 10$ ), and the remaining 47 were in Year 2 (Y2) (the equivalent of grade 1 in the USA; mean age $7 ; 1$ years, from $6 ; 5$ to $7 ; 10$ ). An approximately equal number of girls and boys was tested in each group (RY: 21 girls and 19 boys; Y2: 21 girls and 26 boys). All children were monolingual speakers of English, born and raised in Plymouth or its close surroundings. Together with their active consent form, parents were asked to fill in a questionnaire to identify their own accent (for both mother and father, if relevant).

\section{Stimuli}

A set of 38 sentences was constructed (see Appendix); 12 were used for the gender categorization baseline phase, and 26 for the accent categorization test phase. Sentences were on average 16.6 syllables long (from 12-20 syllables), and contained from zero to three levels of embedding. For the gender categorization baseline phase, two female speakers and two male speakers recorded three sentences each. These speakers, aged 27-39, had a standard British English accent (see Hughes \& Trudgill, 1996, for a description). Two sentences (one uttered by one of the female speakers, one uttered by one of the male speakers) served as examples. The remaining 10 sentences were presented randomly to each child.

For the accent categorization test phase, only female speakers were recorded, two speakers from the Plymouth area (aged 40 and 41), two Irish speakers (aged 51 and 35, in Plymouth for 25 years and two years respectively), and two French speakers, having learned English as a second language during puberty and proficient (aged 35 and 37, in Plymouth for respectively 12 years and 4 months at the time of recording). Out of the 26 sentences, 14 were recorded by all French and Irish speakers, and the remaining 12 were recorded by all Plymouth speakers.

When compared with the standard British English accent, the Plymouth regional accent, as most of the English West Country regional accents, is usually characterized as having a slow rate of speech, with lengthened vowel sounds (West Country entails Cornwall, Devon, Bristol, Somerset and Dorset, plus parts of Wiltshire and Gloucestershire). A full description can be found in Upton and Widdowson (1996). The two Irish speakers engaged for the production of stimuli originated from the areas of Dublin and Cork. According to Trudgill and Hannah (1985), the regional accents spoken in these southern Ireland areas can be categorized as originating from the same English-English varieties (as opposed to regional accents spoken in the North, which originate from Scottish-English). Details of the vowel and consonant systems characterizing these regional accents are extensively presented in Trudgill and Hannah (1985).

\section{Procedure}

Children were tested individually in a quiet room at school, or in the BabyLab within the University of Plymouth, after active consent had been obtained from the carers. The experimenter explained that a cheeky monkey had been playing at night with the laptop, and had mixed up everything inside. The child was asked whether she/he was willing to help sort things up. Then the experimenter explained the following: "You will hear people speaking, and when it is a boy who speaks, you have to press the blue key. If it is a girl, press the red key." Two examples were provided, a male voice and a female voice, and the experimenter showed the child which keys to press. Then the experimenter put headphones on the child's head and asked him/her to keep on going by themselves. During this baseline gender categorization phase, 10 sentences were presented, half of which were produced by two women and the other half by two men. One of the speakers from each gender was identical to those used in the examples, and the two other speakers were new. This was done to ensure that children would generalize the task to new speakers, rather than learn to recognize particular voices provided during the examples. Feedback was delivered on the screen after each key press (a happy or sad character with a happy or sad jingle). When the baseline was completed, the experimenter removed the headphones from the child's head, congratulated him/her and told him/her about the following task:

Now, it will be only girls speaking. No more boys. And this time, some of the girls are from Plymouth, so they speak like you, like the headteacher, like your teacher. The other girls are aliens (with a dramatic voice). They come from another planet, therefore they don't speak exactly like you. So if it is a girl from Plymouth, we press the blue key. If it is an alien girl, we press the red button, OK? Let's try together first to see how to do that.

Four examples were provided, with one Plymouth speaker uttering two sentences, and a speaker with an Irish accent or 
a French accent uttering the other two sentences (depending on the group the child was assigned to). Then the child put the headphones back on, and started the test phase by him/herself. Each child was presented with 22 sentences to categorize, 10 produced in the Plymouth accent and 12 in the unfamiliar accent (this proportion was chosen to make the task more interesting). The experimenter was unable to hear the sentences, but she could see the feedback on the screen and therefore encourage the child to persevere. When the experiment was completed, the child was congratulated and offered a small toy as a thank you. She/he was then told that the speakers were not really aliens, but were from another country/region, and none of them expressed any surprise. The entire experiment lasted no longer than 15 minutes. The reason why we chose to describe the French or Irish speakers as aliens is because pilot work had showed that if we were referring to speakers coming from another region or another country, the youngest children would not necessarily understand what the task was. By referring to aliens, children assumed immediately that there would be something "funny" about their speech style.

Children were randomly assigned to one of two groups: in the Irish group, they were presented during the test phase with Irish voices versus Plymouth voices. In the French group, the test phase consisted of French voices versus Plymouth voices. In addition, within each group, an equal number of children were assigned to one of two conditions, depending on the identity of the speakers used as examples during the test phase. In the Irish group, for example, in the Irish A condition, one Irish speaker and one Plymouth speaker were used to produce the example sentences, whereas in the Irish B condition, the second Irish speaker and the second Plymouth speaker were used. This was done to ensure that children could categorize accents across both speakers, and not simply use properties from one particular (set of) voice(s). These two speaker modalities within each accent group will be referred to as Speakers A and Speakers B.

One problem when working with accented speech is to control for between-speaker variability, and for comparability of the speech samples. In an attempt to quantify the amount of unfamiliar features in each speaker productions, we conducted an accentedness rating study with a pool of adult participants. Results of this accent rating study are presented in the results section.

\section{Results}

\section{Accent rating}

In order to verify that the accent samples were similar on their level of accentedness, 16 adults originating from the South-
West (mean age 27, including 11 females) were asked to rate a random subset of 30 sentences uttered by each of our six speakers (five per speaker). After each sentence was delivered, the origin of each accent was displayed onscreen (French, Irish or Plymouth), and the listeners were asked to rank the sentence on a scale of 1 to 4 ( 1 being the lowest) according to the level of "Irishness", "Frenchness" or "Plymouthness" they estimated in each sentence. When rating the Plymouthian speakers the listeners were explicitly asked to give a maximum score (4) if the accent sounded very familiar, therefore very Plymouthian. The raters judged the Irish speakers as having a stronger accent than the French speakers $(F(1,15)=8.74, p=$ .0098), while the accent of Plymouthian speakers was rated weaker than both the Irish $(F(1,15)=12.38, p=.003)$ and the French $(F(1,15)=8.01, p=.013)$. This, of course, could be attributed to the fact that people have difficulties in rating their own accent. However, an additional pool of six British listeners from outside the South-West (mean age: 28 , including one female) also rated the Plymouthian accent as lower than that of the Irish or the French speakers (mean rate for the Plymouth speakers: 2.18; Irish: 2.68; French: 2.47). The comparability of the perceptual scales applied to the two types of accents can certainly be discussed; however, this rating test indicates that the accentedness was equally moderate across speakers and accents.

\section{Accent categorization}

The children's performance during the gender categorization baseline and accent categorization test phase was first measured as the percentage of correct answers for gender or accent categorization, that is, the total number of correct hits was divided by the total number of possible responses (see Table 1). During the gender categorization baseline, the mean correct responses were $93.7 \%$ in Reception Year children and $98.1 \%$ in Year 2 children, showing that children understood the general principles of the task. During the accent categorization test phase, performance improved with age, $58.4 \%$ for the Reception Year group and $77.4 \%$ for the Year 2 group (effect of age group: $F(1,79)=21.0, p<.001, \eta_{\mathrm{p}}{ }^{2}=.21$, power $=.99)$. Overall, children assigned to the French accent group performed better $(73.5 \%)$ than those assigned to the Irish accent group $\left(64.1 \%, F(1,79)=3.90, p=.05, \eta_{\mathrm{p}}^{2}=.05\right.$, power $=.50)$, irrespective of age (interaction between age and condition: $F(1,48)<1)$.

Measures of correct responses do not exclude potential effects of response bias, that is, participants' tendency to overestimate - or under-estimate - the number of unfamiliarly accented sentences. To evaluate children's ability to detect the unfamiliar accent among all sentences with a bias-free

\section{Table 1}

Percentage of correct responses during baseline and test phase as a function of age and accent group, after outlier rejection; mean $\mathrm{A}^{\prime}$ values during the test phase as a function of age and accent group. Standard deviations are indicated in italics

\begin{tabular}{|c|c|c|c|c|}
\hline & $\begin{array}{l}\text { Correct responses } \\
\text { on baseline (\%) }\end{array}$ & $\begin{array}{l}\text { Correct responses } \\
\text { on test phase (\%) }\end{array}$ & $\begin{array}{l}\text { Mean } \mathrm{A}^{\prime} \text { value } \\
\text { during test phase }\end{array}$ & $\begin{array}{c}\text { Mean } \mathrm{B}_{\mathrm{D}}^{\prime \prime} \text { during } \\
\text { test phase }\end{array}$ \\
\hline RY children, French accent group $(n=18)$ & $92.6-8.5$ & $60.6-18.9$ & $0.63-0.23$ & $-0.14-0.53$ \\
\hline Y2 children, French accent group $(n=23)$ & $98.7-4.6$ & $83.6-13.8$ & $0.89-0.12$ & $0.14-0.77$ \\
\hline Y2 children, Irish accent group $(n=21)$ & $98.1-5.1$ & $71.7-14.8$ & $0.78-0.15$ & $-0.09-0.53$ \\
\hline
\end{tabular}


measure, separate measures of sensitivity $\left(A^{\prime}\right)$ and bias $\left(B^{\prime \prime}{ }_{D}\right)$ were computed using signal detection analysis. Sensitivity $A^{\prime}$ was used because it does not rely on the strict assumptions of normality and equal variance of signal and noise distributions that are associated with $d^{\prime}$, a more popular measure of signal detection (Grier, 1971). Besides, the $A^{\prime}$ measure, which varies between 0 and 1 , can be computed for extreme values, contrary to $d^{\prime}$. A maximum value of 1.0 is obtained when the participant gives $100 \%$ of correct hits and 0 false alarms, and a value of .5 indicates chance performance. Response bias was measured using $B^{\prime \prime}{ }_{D}$, which is independent from $A^{\prime}$, and ranges from -1 to 1 . Negative values indicate a liberal response bias and positive values indicate a conservative bias (Donaldson, 1992).

In our study, a hit was defined as a "yes" response when the unfamiliar regional or foreign accent was correctly detected. A false alarm occurred when the home accent was mistakenly identified as an unfamiliar regional or foreign accent.

An ANOVA was performed on the distribution of individual $A^{\prime}$ and $B^{\prime \prime}{ }_{D}$, with age group (Reception Year and Year 2) and accent condition during the test phase (Irish or French) ${ }^{1}$ as between-participant factors.

In each age group, outliers for $A^{\prime}$ values were identified (above or below two standard deviations around the mean of the group) and rejected (one participant in the RY group, and three participants in the Y2 group, all having very low $A^{\prime}$ values). Table 1 shows the mean values of $A^{\prime}$ and $B^{\prime \prime}{ }_{D}$ for each accent group and each age group. A marginal main effect of accent group was found on $A^{\prime}\left(F(1,79)=3.92, p=.051, \eta_{\mathrm{p}}{ }^{2}\right.$ $=.047$, observed power $=0.50)$, showing that children assigned to the French accent group performed better than those assigned to the Irish accent group (mean $A^{\prime}=0.78$ versus 0.68 respectively). A main effect of age group was also found $\left(F(1,79)=31.06, p<.001, \eta_{\mathrm{p}}{ }^{2}=.28\right.$, power $\left.=.99\right)$, due to the fact that Year 2 children performed better than Reception Year children (mean $d^{\prime}=0.60$ versus 0.84 respectively). The interaction between age and accent group was not significant $(F(1,79)<1)$. As can be seen in Table 1 , the tendency to be more accurate with the foreign accent than with the regional accent can be seen both in the RY group and the Y2 group, although it is significant for the Y2 children only $(F(1,40)=$ $7.16, p=.011, \eta_{\mathrm{p}}^{2}=.15$, power $=.74$; accent effect in the RY group: $F(1,35)<1)$.

Similar analyses using bias as a dependent measure revealed no main effect of age or accent group (in both cases, $F(1,79)<$ $1)$, and no interaction between these two factors $(F(1,79)=$ $1.71)$.

\section{Effect of dialect exposure upon categorization accuracy}

We also explored how previous exposure to accents could impact upon children's accuracy in an accent categorization task. Clopper and Pisoni (2007) reported that in young American adults, direct exposure to different regional varieties, as measured by geographical mobility during life, affects the perception and representation of dialect variation. Evans and Iverson (2004) found that the amount of exposure to different

\footnotetext{
${ }^{1}$ Another between-participant factor was the speaker identity, that is, which pair of speakers had been presented as examples before the test phase (speakers A or speakers B, for each accent condition). This factor did not have any main effect, nor did it interact with any other factor, therefore it will not be included in the analyses thereafter.
}

varieties of British English would relate to the ability to match stimuli to the dialect of a preceding sentence (see also Clopper \& Pisoni, 2004; Williams, Garrett, \& Coupland, 1999). Because it is naturally difficult to find large groups of children having had a significant history of geographical mobility, we examined rather whether dialect variability within the family circle as opposed to the local surroundings would have an effect upon children's ability to detect accents. More specifically, we distinguished between children raised in a "monodialectal" environment, that is, both parents speaking a variety of the British West Country accent, and children raised in a "bidialectal" family, that is, at least one of the parents speaking another variety of British English. We hypothesized that, if anything, bidialectal children might have a more accurate perception ability for regional variations of their native language than monodialectal ones. Performance of the two groups might be similar for foreign accents, not only because their level of exposure to non-native accents might be similar, but also because according to the hypothesis of non-native filter proposed by Chambers (2002), detection of a foreign accent would be an in-built characteristic of the developing speech perception device.

In order to examine whether exposure to dialect variability might enhance children's ability to perceive and exploit this information, we performed post-hoc analyses on participants' performances, making use of the questionnaire data that was sent out to parents prior to the experiment. Participants were considered as monodialectal if parents both reported having a Plymouth or an English West Country accent $(n=38)$, and bidialectal if at least one of them reported having an accent from another area of the UK $(n=45)$. An ANOVA was performed on $A^{\prime}$ scores with accent group, age and dialect exposure (mono versus bidialectal) as between-participant factors. No effect of dialect or interaction with another factor was significant. The poor overall performance of the 5-yearolds may have induced a floor effect which would prevent any effect to emerge. However, interestingly, the bidialectal 7-yearold children showed a tendency to perform better than the monodialectal ones (mean $A^{\prime}=0.89$ versus 0.81 respectively). Variance in each group (monodialectal versus bidialectal) was not equally distributed (Levene's test for equality of variances: $F(1,42)=12.22, p=.001)$, showing more dispersion in the monodialectal group than in the bidialectal group. A $t$-test performed on the distribution of $A^{\prime}$ showed a main effect of dialect group $(t(41.98)=2.24, p=.03)$. This trend appeared to be consistent for both accents presented during the experiment (French accent group: mean $A^{\prime}$ for the monodialectal children $=.87$; bidialectal children: .91 ; Irish accent group: mean $A^{\prime}$ for the monodialectal children $=.76$; bidialectal children: .85).

\section{Discussion}

In this study, 5- to 7-year-old British Plymouth-raised children were involved in a sentence categorization task in which they were presented with their home accent versus an Irish accent, or with their home accent and a French accent. The 5-year-olds perform poorly in this task, showing low levels of sensitivity to the different accents, although they succeeded in the gender categorization baseline, suggesting that they understood the principle of the task and were sensitive to other kinds of indexical variation in speech. The 7-year-old children, on the other 
hand, showed that they were able to attend to accent-related information in continuous speech, a finding that complements the well-documented demonstration of growing metaphonological abilities during childhood (e.g., Content, 1985; Goikoetxea, 2005). Of particular interest here is the asymmetry in attending to regional accent versus foreign accent cues, which was not found in the 5-year-old group, but which was evidenced in the 7-year-old group. In what follows, we will discuss this developmental effect, and how these results are in line with previous findings showing that French 5-year-olds display better categorization capacities for a foreign English accent as compared to a regional French variation (Girard et al., 2008). We will also address the role of the amount of exposure found in the current study, and finally propose some explanations of why children seem to perceive and represent regional and foreign accents with different levels of awareness.

How can we account for the age effect found in the present study, that is, the higher performance of accent categorization in 7-year-olds as opposed to the relative failure of 5-year-olds? The first obvious reason would be that 5-year-olds lack the amount of exposure to dialect variability that might help them in building representations of accents and grasping the concept of geographical diversity linked with language and dialect variability. However, as Flege (1984) points out, accurate identification of a (foreign) accent in adults might need extended exposure, but simple detection is possible in non-experienced listeners, even in very short samples, such as syllables or segments. Therefore, even with minimal exposure, one would expect 5- to 6-year-old children to be able to detect an unusual variety of their native language. The second more plausible possibility is that younger children's perceptual threshold for accent-related features detection is higher than that of older children, due to biological maturation or increasing attention to speech sounds. Indeed, meta-phonological abilities, which refer to the capacity to pay attention to the formal properties of speech rather than to the meaning it conveys, develop continuously through childhood (e.g., Content, 1985).

The present study also suggests a linguistic/cultural difference in the age at which children display the ability to perceive accent-related differences: 7 for the English children and 5 for the French. However, the different results between the French study and the British study are not so much due to age rather than to design factors: the French 5-year-olds also failed to discriminate a regional French accent from their home accent, just as the 5-year-old British children failed to distinguish their home accent from an Irish accent. However, the French 5year-olds succeeded with the foreign English accent, in contrast to the British 5-year-old children with the foreign French accent, presumably because the level of accentedness in the foreign accent presented to the French children was much higher than the level of accentedness in the foreign accent presented to the British children. If the French 5-yearolds had been presented with a moderate English accent, our prediction is that they would have failed to distinguish it from their home accent. Similarly, if the British 5-year-olds had been presented with a strong French accent, they probably would have succeeded in the categorization task. These statements about the behaviour of the 5-year-old groups remain speculation, therefore at this point, the strongest evidence for the existence of an awareness asymmetry between regional and foreign accent comes from the performance of the 7 -year-old British children group tested in this study.

Another possible avenue of research opened by this study is that the amount of dialect exposure seemed to have an effect upon accent categorization abilities. More precisely, children whose family linguistic environment matches the surroundings did not perform as well as those who had been exposed to a greater variability thanks to their parents' accent. Although these effects were not very strong, they were in the expected direction, which suggests that from the earliest age, as well as in adulthood (Clopper \& Pisoni, 2007; Williams et al., 1999), the perceptual space for accent representation can be modified with experience. This relates to studies on bilingualism suggesting that bilingual children display more developed meta-phonological abilities than their monolingual counterparts (e.g., Bialystok, Majumder, \& Martin, 2003), which could be due to a greater exposure to phonetic and phonological variability than in the case of monolingualism. It must be noted that contrary to our prediction, the amount of exposure to accent variability did not impact differently on children's abilities to categorize regional versus foreign accent, an hypothesis related to the existence of an in-built foreign accent filter in childhood (Chambers, 2002). However, the low statistical power of the analyses prevents us from drawing firm conclusions here.

The main result of this study is the asymmetry in awareness for regional and foreign accents evidenced in 7-year-old children. A greater awareness for foreign accents signals that children are more sensitive to the acoustic correlates of nonnative speech. In adults, lexical access perturbation has also been found to be stronger with foreign accents than with regional accents (Butler \& Floccia, in preparation; Floccia et al., 2006), which suggest that processes of accent normalization are made more difficult with non-native variations than with native ones. To take a classic view in linguistics, the features that may be modified by an unfamiliar accent are twofold: supra-segmental or segmental. Distortion of suprasegmental features in foreign accented speech might be responsible for lexical access delays or impairment. For instance, late French learners of English usually have a great difficulty in producing the stress pattern of English syllables in the correct place (see Dupoux et al., 1997), which may cause some disruption in the lexical access processes of English listeners. However, debriefing after the accent rating experiment conducted with adults suggested that the main features people used to identify and rate the French foreign accent was related to phonemic use rather than prosody (thus segmental rather than supra-segmental). Most people reported that the French speakers were revealed by how they produced some particular words, as overall, they found that their accent was not overtly remarkable. This suggests that our (experienced) speakers were rather efficient in producing the proper prosodic and rhythmical patterns of native English.

Regarding segmental information, a possibility is that the level of phonemic redundancy usually found in speech (e.g., Cherry, Halle, \& Jakobson, 1953) is comparatively more important in regional varieties than in foreign accented forms. This is due to the fact that whereas the phonological differences between two regional accents involve mainly changes in the vowel repertoire and/or use, at least as far as English and French are concerned (see Wells, 1982, for English; Carton, Rossi, Autesserre, \& Leon, 1983, for French), foreign accented speech may be characterized by changes in both consonants and vowels, contributing to lowering the level of redundancy. Interestingly, it has been suggested recently that vowels and consonants play a different role in language processing and 
language acquisition (Nespor, Peña, \& Mehler, 2003), with consonants being more important at the lexical level and vowels at the prosodic and syntactic levels (see the recent debate between Bonatti, Peña, Nespor, \& Mehler, 2007 and Keidel, Jenison, Kluender, \& Seidenberg, 2007; see also Toro, Nespor, Mehler, \& Bonatti, 2008). Supporting this view, Nazzi (2005) has demonstrated that young children perform better in a word learning task when the to-be-learned words contrast on consonants rather than on vowels (see also Nazzi \& New, 2007; Nazzi, Floccia, Moquet, \& Butler, in press; but see Mani \& Plunkett, 2007, for a different view). Research on adults also suggests that English, Dutch or Spanish adults, when asked to turn auditorily-presented nonwords (e.g., "kebra") into words, tend to replace vowels (e.g., "cobra") rather than replace the consonants (e.g., "zebra") (Cutler, Sebastian-Gallés, SolerVilageliu, \& Van Ooijen, 2000; van Ooijen, 1996). Observations of secret languages, which are popular with children, suggest that most often these languages are made up of insertions of a new syllable after each syllable, so that the onset of this inserted syllable is fixed and the vowel is a replication of the preceding syllable's vowel (McCarthy, 1991). According to Nespor et al. (2003), this is because introducing a varying consonant would impair lexical identification.

In this perspective, the asymmetry found in children for awareness of regional versus foreign accents could be interpreted as being the results of greater distortions of consonants in foreign-accented speech than in regional-accented speech, causing more lexical identification impairments in the former, and then, drawing more attention towards this particular form of accent. To test this hypothesis, we performed some acoustic measures on selected vowels (/æ/ and /I/) and plosive consonants in the stimuli used in the experiment (see Appendix). We expected to find that accents would differ equally from each other in the vowel realizations, while the foreign French accent would be characterized by a greater variability in consonant realization than the Irish regional accent, as compared to the Plymouth home accent. The main results of the analyses were that accents (home versus Irish and home versus French) could be differentiated on the basis of first and second formant (F1 and F2) distributions for both vowels. Irish speakers differed from the Plymouth set by F1 values on $/ \mathrm{I} /$, and by $\mathrm{F} 2$ on $/ \mathfrak{x} /$; French speakers produced different /æ/ than the Plymouth speakers, for both F1 and F2 values. This analysis confirms the first part of our hypothesis, that is, that there are similar levels of variability between the vowels of the two unfamiliar accents. Regarding consonant analyses, Voice Onset Time measurements on tokens of each six plosive consonants $(/ \mathrm{p} /, / \mathrm{t} /, / \mathrm{k} /, / \mathrm{b} /, / \mathrm{d} /, / \mathrm{g} /)$ revealed that, apart from $/ \mathrm{t} /$, the Irish speakers produce VOT closer to the Plymouth VOT than the French speakers. This supports the second part of our hypothesis, namely that consonant cues might be more informative when distinguishing between a foreign and a native accent, rather than between regional variations of the native accent.

\section{Conclusion}

Acoustic analyses carried out on steady-state vowel formants and consonant VOT among the different accents used in this study show that vowel formant space differed from one accent to the other, whereas VOT values for the Irish and Plymouth accents tended to be closer to each other than those produced by the French speakers. These results are in favour of the hypothesis according to which foreign accents might be characterized by a range of acoustic and phonetic variability bearing on all kinds of phonemes, consonants and vowels, whereas regional accents might be mainly defined in terms of vowel variability. In Nespor et al.'s (2003) proposal of a distinctive functional role of vowels and consonants in speech processing, this might result in foreign accents triggering more lexical access failures or delays than regional access, leading to a greater awareness of this variety of accent.

So far, discussions about the origins of the distinctive functional role of vowels and consonants in adults have focused upon distributional differences between languages (e.g., Bonatti et al., 2007; Keidel et al., 2007). For example if consonants outnumber vowels in a particular language, this might result in a greater lexical informative load carried by consonants, hence leading to a more important role of consonants in lexical identification. Our findings suggest that the study of the potential role played by the acoustic-phonetic variability in the realization of these segments can also be informative when attempting to account for the functional asymmetry between these two categories of phonemes. If acoustic variability in vowels is such that their robust identification is less reliable than that of consonants, this would also lead to a more important role played by consonants in lexical identification processes.

More systematic measures of accent-related acoustic correlates would be needed to back up this hypothesis. What can be acknowledged so far is that accent perception in childhood seems to be characterized by a growing awareness of regional varieties of the maternal language, as compared to a more stable ability to detect foreign accented versions of it. The consequence of this might be the progressive loss of the capacity to learn a new dialect when moved from one region to the other (as shown by Payne, 1980, for example), and a relative inability to develop a foreign accent in the native language from the earliest age (as noted by Chambers, 2002). Growing meta-phonological awareness would be one of the keys to explain the loss of perceptual plasticity for speech processing in childhood. A similar proposal was put forward by Bley-Vroman (1988) to explain the decline in syntactic acquisition abilities between childhood and adulthood. Known as the Fundamental Difference Hypothesis (FDH), this hypothesis states that adults, contrary to children, use problemsolving strategies when learning a second language because they can no longer rely upon innate mechanisms for implicit language acquisition. The passage from childhood to adulthood is characterized by a progressive diminishing capacity for implicit learning of complex abstract systems due to maturational constraints. While the FDH has been formulated and tested on the child's ability to acquire syntax, we propose that it could be extended to their learning of languages' sound systems. Children's capacities for learning the sound system of a language or a regional accent lie in their incapacity to access this information explicitly. By extension, their awareness for foreign accents relates to their inability to learn them.

\section{References}

Adank, P., \& McQueen, J.M. (2007). The effect of an unfamiliar regional accent on word comprehension. Paper presented at the ICPhS XVI, Saarbrucken, 6-10 August.

Bialystok, E., Majumder, S., \& Martin, M.M. (2003). Developing phonological awareness: Is there a bilingual advantage? Applied Psycholinguistics, 24(1), 27-44. 
Bley-Vroman, R. (1988). The fundamental character of foreign language learning. In W. Rutherford \& M.S. Smith (Eds.), Grammar and second language teaching: $A$ book of readings (pp. 19-30). Rowley, MA: Newbury House.

Boersma, P. (2001). Praat, a system for doing phonetics by computer. Glot International, 5(9/10), 341-345.

Bonatti, L.L., Peña, M., Nespor, M., \& Mehler, J. (2007). On consonants, vowels, chickens and eggs. Psychological Science, 18(10), 924-925.

Butler, J., \& Floccia, C. (in preparation). Regional and foreign accent processing in short term memory.

Butler, J., Metz, J., \& Floccia, C. (2008). The effects of accent related variation on speech perception in 5 and 7 month olds. Poster presented at the International Conference on Infant Studies, Vancouver, Canada.

Carton, F., Rossi, M., Autesserre, D., \& Léon, P. (1983). Les accents du Français. Paris: Hachette.

Chambers, J.K. (1992). Regional accent acquisition. Language, 68(4), 673-705.

Chambers, J.K. (2002). Dynamics of dialect convergence. Fournal of Sociolinguistics, 6, 117-130.

Cherry, E.C., Halle, M., \& Jakobson, R. (1953). Toward the logical description of languages in their phonemic aspect. Language, 29(1), 34-46.

Clarke, C.M., \& Garrett, M.F. (2004). Rapid adaptation to foreign-accented English. The Fournal of the Acoustical Society of America, 116, 3647-3658.

Clopper, C.G., \& Pisoni, D.B. (2004). Homebodies and army brats: Some effects of early linguistic experience and residential history on dialect categorization. Language Variation and Change, 16, 31-48.

Clopper, C.G., \& Pisoni, D.B. (2007). Free classification of regional dialects of American English. Fournal of Phonetics, 35, 421-438.

Content, A. (1985). Le développement de l'habileté d'analyse phonétique de la parole [The development of the ability to analyse speech phonetically] L'Année Psychologique, 85, 555-572.

Cutler, A., Sebastian-Gallés, N., Soler-Vilageliu, O., \& Van Ooijen, B. (2000). Constraints of vowels and consonants on lexical selection: Cross-linguistic comparisons. Memory and Cognition, 38(5), 746-755.

Deterding, D. (2006). The north wind versus a wolf: Short texts for the description and measurement of English pronunciation. Fournal of the International Phonetic Association, 36(2), 187-196.

Donaldson, W. (1992). Measuring recognition memory. Fournal of Experimental Psychology: General, 121(3), 275-277.

Dupoux, E., Pallier, C., Sebastian-Gallés, N., \& Mehler, J. (1997). A destressing "deafness" in French? fournal of Memory and Language, 36, 406-421.

Evans, B.G., \& Iverson, P. (2004). Vowel normalisation for accent: An investigation of best exemplar locations in northern and southern British English sentences. Fournal of Acoustical Society of America, 115, 352-361.

Fischer, J.L. (1958). Social influences on the choice of a linguistic variant. Word, $14,47-56$.

Flege, J.E. (1984). The detection of French accent by American listeners. Fournal of the Acoustical Society of America, 76(3), 692-707.

Flege, J.E., Yeni-Komshian, G., \& Liu, S. (1999). Age constraints on second language learning. Fournal of Memory and Language, 41, 78-104.

Floccia, C., Butler, J., Goslin, J., \& Ellis, L. (in press). Regional and foreign accent processing in English: Can listeners adapt? Fournal of Psycholinguisticc Research.

Floccia, C., Goslin, J., Girard, F., \& Konopczynski, G. (2006). Does a regional accent perturb speech processing? Fournal of Experimental Psychology: Human Perception and Performance, 32, 1276-1293.

Girard, F., Floccia, C., \& Goslin, J. (2008). Perception and awareness of accents in young children. British fournal of Developmental Psychology, 26(3), 409-433.

Goikoetxea, E. (2005). Levels of phonological awareness in preliterate and literate Spanish-speaking children. Reading and Writing, 18, 51-79.

Grabe, E., \& Post, B. (2002). Intonational variation in English. In B. Bel and I. Marlin (Eds.), Proceedings of the Speech Prosody 2002 Conference, 11-13 April 2002, Aix-en-Provence: Laboratoire Parole et Langage, 343-346.

Grier, J.B. (1971). Nonparametric indexes for sensitivity and bias: Computing formulas. Psychological Bulletin, 75, 424-429.

Gurski, C. (2006). The hybrid system of voice onset time in French/English bilinguals. The fournal of the Acoustical Society of America, 119(5), 3392.

Hughes, G.A., \& Trudgill, P. (1996). English accents and dialects. An introduction to social and regional varieties of English in the British Isles (3rd ed.). London: Arnold.

Jongman, A., Wade, T., \& Sereno, J. (2003). On improving the perception of foreign-accented speech. Paper presented at the 15th International Congress of Phonetic Sciences, Barcelona, Spain.

Keidel, J.L., Jenison, R.L., Kluender, K.R., \& Seidenberg, M.S. (2007). Does grammar constrain statistical learning? Commentary on Bonatti, Peña, Nespor and Mehler (2005). Psychological Science, 18(10), 922-923.

Kerswill, P., \& Williams, A. (1992). Some principles of dialect contact: Evidence from the new town of Milton Keynes. Reading: Department of Linguistic Science, University of Reading.

Kinzler, K.D., Dupoux, E., \& Spelke, E.S. (2007). The native language of social cognition. Proceedings of the National Academy of Sciences, 104(30), 12577-12580.
Kitamura, C., Panneton, R., Notley, A., \& Best, C. (2006). Aussie, Aussie, Aussie, Oi-Oi-Oi: Infants love an Australian accent. The fournal of the Acoustical Society of America, 120(5), 3135.

Mani, N., \& Plunkett, K. (2007). Phonological specificity of vowels and consonants in early lexical representations. Fournal of Memory and Language, 57(2), 252-272.

Maye, J., Aslin, R.N., \& Tanenhaus, M.K. (2008). The weckud wetch of the wast: Lexical adaptation to a novel accent. Cognitive Science, 32, 543-562.

McCarthy, J. (1991). L'infixation réduplicative dans les langages secrets [Reduplicative infixation in secret languages]. Langages, 101, 11-29.

Meunier C., \& Floccia, C. (1997). La spécificité des types de parole pour la perception de la voyelle [Specificity of speech styles for vowel perception]. In Proceedings of the 1ères fournées d'Etudes Linguistiques, "La voyelle dans tous ses états” (pp. 158-163). University of Nantes, Nantes, France.

Nazzi, T. (2005). Use of phonetic specificity during the acquisition of new words: Differences between consonants and vowels. Cognition, 98, 13-30.

Nazzi, T., Floccia, C., Moquet, B., \& Butler, J. (in press). Bias for consonantal over vocalic information in 30-month-olds: Crosslinguistic evidence from French and English. Fournal of Experimental Child Psychology.

Nazzi, T., Jusczyk, P.W., \& Johnson, E.K. (2000). Language discrimination by English-learning 5-month-olds: Effects of rhythm and familiarity. Fournal of Memory and Language, 43, 1-19.

Nazzi, T., \& New, B. (2007). Beyond stop consonants: Consonantal specificity in early lexical acquisition. Cognitive Development, 22(2), 271-279.

Nespor, M., Peña, M., \& Mehler, J. (2003). On the different roles of vowels and consonants in speech processing and language acquisition. Lingue e Linguaggio, 2, 203-229.

Payne, A. (1980). Factors controlling the acquisition of the Philadelphia dialect by out-of-state children. In W. Labov (Ed.), Locating language in time and space (pp. 143-178). New York: Academic Press.

Phan, J., \& Houston, D.M. (2006). Infant dialect discrimination. Paper presented at the Annual meeting of the XVth Biennial International Conference on Infant Studies, Kyoto, Japan.

Starks, D. (2002). Individual variation in the acquisition of postvocalic /r/: Day care and sibling order as potential variables. American Speech, 77(2), 184-194.

Toro, J.M., Nespor, M., Mehler, J., \& Bonatti, L.L. (2008). Finding words and rules in a speech stream: Functional differences between vowels and consonants. Psychological Science, 19(2), 137-144.

Trudgill, P. (1986). Regional accents in contact. Oxford: Basil Blackwell.

Trudgill, P., \& Hannah, J. (1985). International English: A guide to varieties of standard English. London: Edward Arnold.

Upton, C., \& Widdowson, J.D.A. (1996). An atlas of English regional accents. Oxford: Oxford University Press.

Van Ooijen, B. (1996). Vowel mutability and lexical selection in English: Evidence from a word reconstruction task. Memory and Cognition, 24(5), 573-583.

Wells, J.C. (1982). Accents of English, volume 1: An introduction. Cambridge: Cambridge University Press.

Whiteside, S.P., Henry, L., \& Dobbin, R. (2004). Sex differences in voice onset time: A developmental study of phonetic context effects in British English. Fournal of the Acoustical Society of America, 116(2), 1179-1183.

Williams, A., Garrett, P., \& Coupland, N. (1999). Dialect recognition. In D.R. Preston (Ed.), Handbook of perceptual dialectology (pp. 345-358). Philadelphia: John Benjamins.

\section{Appendix}

\section{Acoustic measures on vowels and consonants}

Sixteen words containing steady states vowels /æ/ $(n=7)$ and $/ \mathbf{I} /(n=$ 9) were selected from the stimuli. Following Deterding's (2006) recommendations for vowel measurements, only clear stressed instances of each monopthong were measured, avoiding vowels preceding or following / $\mathrm{r} /, / \mathrm{w} /, \mathrm{j} /$ (with two exceptions: / $/$ in "Christmas" and in "drink"), and vowels following $/ 1 /$ and $/ \mathrm{y} /$. The mean values of $\mathrm{F} 1$ and F2 were measured with Praat (version 4.6.31; Boersma, 2001) using an LPC formant analysis, for each speaker of each accent. ${ }^{2}$ As

\footnotetext{
${ }^{2}$ Because we had recordings of the same sentences produced by all the six different speakers (two per accent), we could compare directly the realization of $/ \mathfrak{a} /$ and /I/ vowels or consonantVOT in the same environment. However, children were presented with the Irish or the French version of these sentences, not with the Plymouth versions. We have to assume that the vowels or consonants in the other sentences recorded by the Plymouth speakers and presented to the children were very similar to those measured here.
} 
can be seen in Figures 1 and 2, which depict the representation space of $/ \mathfrak{x} /$ and $/ \mathrm{I} /$, the values measured for the Plymouth speakers were quite different from those reported by Deterding (2006) in Received Pronunciation British English (/I/: 396 and $1839 \mathrm{~Hz}$ for F1 and F2 respectively; /æ/: 667 and $1565 \mathrm{~Hz}$ for $\mathrm{F} 1$ and F2), but it must be noted that none of our speakers had an RP pronunciation. Having said that, the Irish speakers are closer to the Plymouth speakers than the French for the $/ \mathfrak{x} /$, but the reverse is found for the $/ \mathrm{I} /$ : Irish speakers are further apart from the French and Plymouth speakers.

An ANOVA with $\mathrm{F} 1$ value for $/ \mathfrak{m} /$ as a dependent measure and speakers' accent as between-item variables showed a main effect of accent $(F(2,32)=5.27, p=.010)$ due to the French speakers differing from the two other sets of speakers (French versus Irish: $t(26)=$ 2.92, $p=.007$; French versus Plymouth: $t(19)=2.60, p=.018)$, who did not differ from each other (Irish versus Plymouth: $t(19)<1$ ). The same analyses with $\mathrm{F} 2$ value as the dependent measure also gave a main effect of accent $(F(2,32)=4.48, p=.019)$, due to a different distribution of values: French and Irish speakers did not differ from each other $(t(26)=1.17)$, whereas Plymouth $/ \mathfrak{x} /$ vowel was produced with different F2 values than the French one $(t(19)=2.58, p=.019)$ or the Irish one $(t(19)=2.38, p=.028)$.

Regarding /I/ vowel, an effect of accent was found on $\mathrm{F} 1(F(2,42)=$ $9.81, p<.001)$, due to a difference between the Irish speakers and two other sets (Irish versus French: $t(34)=3.79, p=.001$; Irish versus Plymouth: $t(25)=2.74, p=.011)$, and no difference between
Plymouth and French $(t(25)<1)$. Similar analyses on F2 did not yield any significant accent effect $(F(2,42)=2.54, p=.091)$.

To summarize, although formant values for $/ \mathrm{I} /$ appeared to be less dispersed than for $/ \mathfrak{x} /$ (see also Meunier \& Floccia, 1997), accents could be differentiated on the basis of F1-F2 distributions for both vowels. Irish speakers differed from the Plymouth set by F1 values on $/ \mathrm{I} /$, and by F2 on /æ/; French speakers produced different /æ/ than the Plymouth speakers, for both $\mathrm{F} 1$ and $\mathrm{F} 2$ values. This analysis confirms the first part of our hypothesis, that is, that vowels might be just as variable between the two unfamiliar accents.

Regarding consonants, the voice onset time (VOT) on word-initial intervocalic plosive consonants was measured for the three sets of speakers. The VOT measurements were taken from a FFT spectrogram representation generated by Praat, and the distance between the release of the plosive to the onset of the voicing was reported. The 14 selected words (all stress initial) were pasta, parcels, towels, tortoise, tiger, kitten, coffee, catch, bottle, bag, basket, donkey, disappointed and give. Figure 3 shows the distribution of VOT values per accent for each of the three voiceless plosives $(/ \mathrm{p} /, / \mathrm{t} /$ and $/ \mathrm{k} /)$ and the three voiced plosives $(/ \mathrm{b} /, / \mathrm{d} /$ and $/ \mathrm{g} /)$.

In five cases out of six, Irish speakers produce VOT closer to the Plymouth VOT than the French speakers. The exception is the /t/ phoneme, for which Irish speakers produced shorter VOT than the French. It must be noted that there were between one and three tokens per phoneme, so outliers have a strong effect on the data. An ANOVA

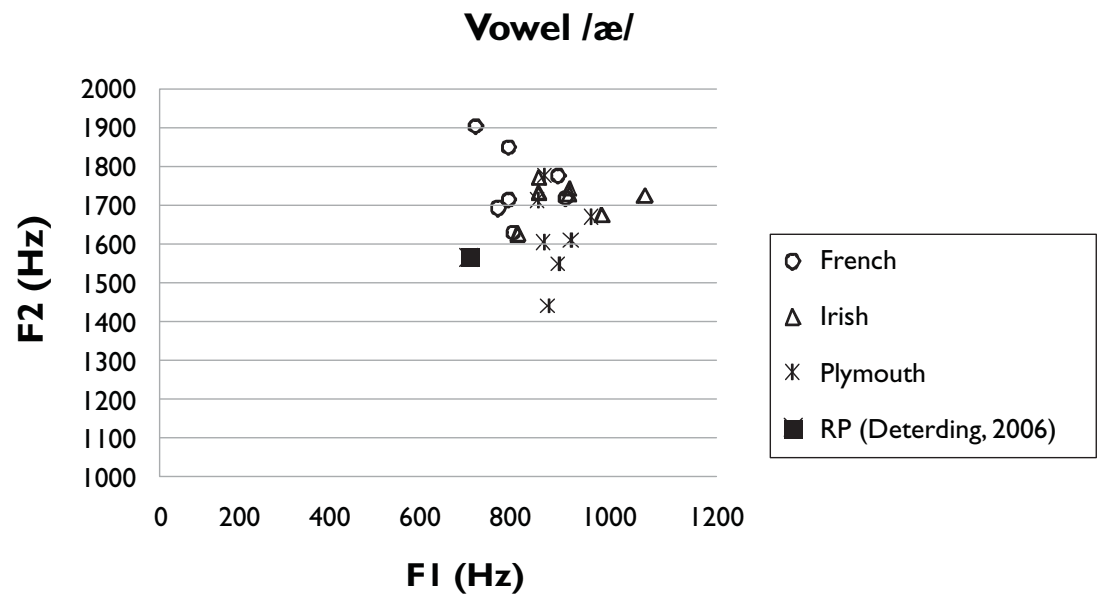

Figure 1. F1-F2 vowel chart for /æ/ measured from three sets of speakers (French, Irish and Plymouthian) producing the same seven words. The reference value provided by Deterding (2006) for Received Pronunciation speakers is represented as a dark square.

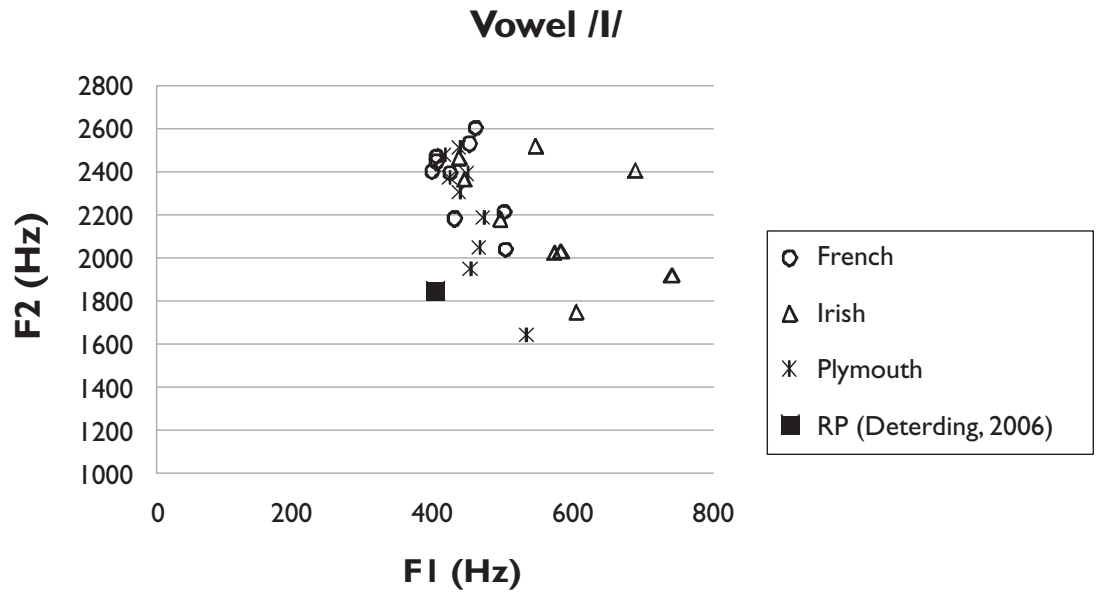

Figure 2. F1-F2 vowel chart for /I/ measured from three sets of speakers (French, Irish and Plymouthian) producing the same nine words. The reference value provided by Deterding (2006) for Received Pronunciation speakers is represented as a dark square. 


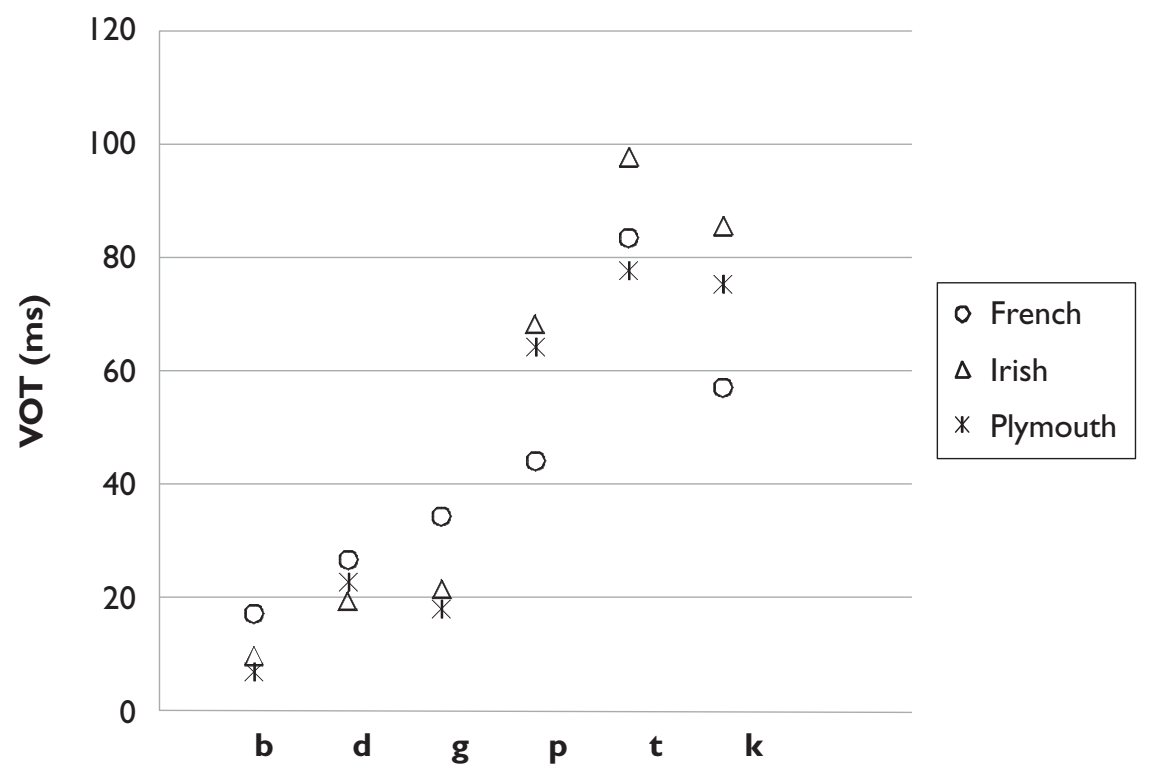

Figure 3. Mean voice onset time (in ms) values for each accent and each plosive type, as measured from word-initial consonants.

with accents (three modalities) and voice (voiceless versus voiced plosives) as independent variables was carried on VOT values. No main effect of accent was reported $(F(2,59)=1.24)$, but the interaction between accent and voice was found to be significant $(F(2,59)=5.89$, $p=.0046)$. The comparison between the French and the Plymouth accents for voiced plosives was marginally significant $(F(1,16)=3.52$, $p=.079)$ and not significant for the voiceless plosives $(F(1,19)<1)$. The Irish and the Plymouth speakers produced similar values of VOT for both the voiced $(F(1,15)<1)$ and the voiceless plosives $(F(1,20)$ $=2.48, p=.13$ ). It must be noted that the VOT values reported for the French speakers are very different from French VOT equivalents: French speakers usually produce zero VOT values for voiceless plosives and negative values for voiced plosives (Gurski, 2006). Our speakers seemed to be targeting the proper English values, but aiming too high for the voiced plosives, and not high enough for the voiceless phonemes. It must be also be noted that due to the poor number of observations per consonant type, no statistical test could be reliably performed to evaluate the accent difference for each phoneme, which is the usual way in phonetics (e.g., Gurski, 2006; Whiteside, Henry, \& Dobbin, 2004).

All measures were performed by two independent raters, and a Pearson's product-moment correlation was used to calculate the level of inter-rater reliability. A significant correlation coefficient (for the vowels: $r=0.998, p<0.0001$; for the consonants: $r=.985, p<.0001$ ) demonstrated a high level of inter-rater reliability. 